\title{
Stage IIB Pancreatic Cancer AJCC v6 and v7
}

National Cancer Institute

\section{Source}

National Cancer Institute. Stage IIB Pancreatic Cancer AJCC v6 and v7. NCI Thesaurus.

Code C88103.

Stage IIB includes: (T1, N1, M0); ( 2 2, N1, M0); (T3, N1, M0). T1: Tumor limited to the pancreas, $2 \mathrm{~cm}$ or less in greatest dimension. T2: T umor limited to the pancreas, more than $2 \mathrm{~cm}$ in greatest dimension. T3: T umor extends beyond the pancreas but without involvement of the celiac axis or the superior mesenteric artery. N1: Regional lymph node metastasis. M0: No distant metastasis. (from AJCC 7th Ed.) 